\title{
EXPRESSÃO DAS CADERINAS NOS TUMORES MAMÁRIOS EM CADELAS
}

\author{
(Cadherin Expression in Canine Mammary Tumors)
}

\author{
PIEKARZ, C. H. ${ }^{1}$; BIONDO, A. W. ${ }^{2}$; AMORIM, R. L. ${ }^{3}$; RODASKI, S. ${ }^{2}$; BARROS FILHO, I. R. ${ }^{2}$; \\ DE NARDI, A. B. ${ }^{4}$
}

1. Curso de Pós-graduação em Ciências Veterinárias, Universidade Federal do Paraná UFPR, Curitiba / PR.

2. Professor Adjunto, Departamento de Medicina Veterinária, UFPR, Curitiba / PR. 3. Professor Adjunto, Departamento de Clínica Veterinária, Universidade Estadual Paulista UNESP, Campus de Botucatu, Botucatu / SP.

4. Professor do Curso de Mestrado em Cirurgia e Anestesiologia Veterinária da Universidade de Franca -

UNIFRAN.

\begin{abstract}
RESUMO - As neoplasias mamárias são as que mais acometem as cadelas. O desenvolvimento do câncer pode levar à ocorrência de metástases que podem ser detectadas por marcadores protéicos. Um destes marcadores é a E-caderina, um membro da família das caderinas conhecida por desempenhar um papel importante na regulação da adesão intercelular em tecidos epiteliais. Estudos apontam que as E-caderinas podem funcionar como moléculas supressoras de tumor e de invasão. A atividade das caderinas é regulada por múltiplos mecanismos, incluindo a interação com outras proteínas como as cateninas. Nesta revisão os autores abordam a família das caderinas, incluindo sua função, fisiopatologia e potencial uso como marcadores de diagnóstico e prognóstico nas neoplasias mamárias na cadela.
\end{abstract}

Palavras-Chave: caderina, imunoistoquímica, neoplasia mamária, cão.

ABSTRACT - Mammary tumors are among the most common neoplasia of canine females. The occurrence of metastasis may be detected by proteic markers. Among them, exist the E-cadherin, a member of cadherin family known for its important role in the regulation of intercellular adhesion in epithelial tissues. Studies suggest that E-cadherin may function as a tumor and invasion suppressor molecule. Cadherin activity is regulated by multiple mechanisms, including interaction with other proteins such as catenins. In this review, the authors approach the cadherin family and other related adhesion proteins including its function, physiopathology and potential use as marker for diagnosis and prognosis of canine mammary tumors. Key words: cadherin, immunohistochemistry, mammary neoplasia, dog

\section{INTRODUÇÃO}

As neoplasias mamárias são os tumores mais comuns nas fêmeas caninas não castradas, sendo consideradas hormônio dependentes. Esta consideração é baseada nas observações de que o risco de ocorrência de neoplasias malignas em cadelas castradas antes do primeiro estro é baixo (em torno de 0,05\%), aumentando após o primeiro cio para $8,0 \%$ e após o segundo para $26,0 \%$ quando comparadas com as cadelas não castradas. Passado este período, a castração parece não interferir mais na oncogênese das neoplasias malignas (RUTTEMAN et al., 2001; SORENMO, 2003). Porém, a chance de desenvolver tumores benignos parece ser reduzida pela castração em qualquer idade (RUTTEMAN et al., 2001).

Os tumores de mama representam aproximadamente $52 \%$ de todas as neoplasias na fêmea canina, sendo que $50 \%$ delas são malignas (RUTTEMAN et al., 2001). E, dentre as malignas, cerca de $50 \%$ são os carcinomas. A classificação pode ser realizada de acordo com a origem tecidual (tecido epitelial, mioepitelial ou mesenquimal), os aspectos morfológicos e o prognóstico (SORENMO, 2003).

Em Medicina Veterinária, o diagnóstico definitivo para tumores mamários é o exame histopatológico, que deve ser realizado em todos os casos de neoplasia mamária submetidas à exérese cirúrgica. O exame microscópico do tumor e da cadeia linfática fornece as informações sobre a sua natureza, seu tipo histológico e a extensão microscópica da lesão (CAVALCANTI e CASSALI; 2006). 
Embora a avaliação microscópica do nódulo auxilie na determinação do prognóstico, diversas proteínas foram propostas recentemente como melhores indicadores de prognóstico nos tumores mamários. Entre elas, várias proteínas de superfície celular responsáveis pela junção celular (as chamadas CAMs - proteínas de adesão celular) têm sido descritas como de potencial uso prognóstico, sendo as cinco principais classes as caderinas, imunoglobulinas, selectinas, mucinas e integrinas (LODISH et al., 2000).

Dentre estas proteínas de junção celular, as caderinas parecem ser as mais promissoras como indicadores de prognóstico de neoplasias mamárias, pois além de atuarem na junção intercelular, estão também envolvidas na regulação de processos observados no desenvolvimento tumoral, como crescimento celular desordenado, diferenciação celular defeituosa e organização tecidual alterada, sendo, portanto, esperado que estas moléculas afetem também a gênese do tumor e o comportamento das células neoplásicas (KNUDSEN e WHEELOCK, 2005).

A presente revisão tem o propósito de oferecer subsídios acerca da fisiopatologia e potencial uso do complexo das caderinas no prognóstico de tumores mamários em cadelas.

\section{CADERINAS}

Durante o desenvolvimento, os tecidos dos organismos multicelulares são formados por uma integração e segregação rigorosamente regulada de populações celulares heterogêneas, como objetivo de formar um modelo celular organizado. Um dos principais mecanismos que estabelece e mantém esses tecidos durante a migração, proliferação e diferenciação celular é a adesão intercelular, normalmente mediada por glicoproteínas de superfície celular (ABERLE et al., 1996).

As caderinas são glicoproteínas transmembranosas (BERX e VAN ROY, 2001; KNUDSEN e WHEELOCK, 2005), cálcio dependentes (LODISH et al., 2000; MATOS et al., 2006), com função de promover essa adesão intercelular (KNUDSEN e WHEELOCK, 2005). São as moléculas que promovem a manutenção da arquitetura tecidual normal (MATOS et al., 2006).

Existem mais de 40 caderinas diferentes conhecidas (LODISH et al., 2000). As caderinas mais estudadas são as E- (epitelial), P- (placentária) e $\mathrm{N}$ - (neural) caderinas, conhecidas como caderinas clássicas (ROWLANDS et al., 2000).

Os ductos e alvéolos mamários que se formam durante o desenvolvimento embrionário são duplamente revestidos por células epiteliais. Estas células se aderem umas às outras pelas E-caderinas
(BOUSSADIA et al., 2002). As células mioepiteliais, que envolvem a camada luminal externa, se aderem umas às outras pelas P-caderinas (RADICE et al., 1997). Sabe-se que a expressão das P-caderinas é restrita ao mioepitélio nas glândulas mamárias normais não lactantes de mulheres, porém tem sido observada em muitos carcinomas ductais (SOLER et al., 2002). Esta observação pode ser um indicativo de que as células tumorais têm características de células mioepiteliais ou de revestimento (RADICE et al., 2003). Sabe-se também que a perda de expressão das P-caderinas resulta em uma alteração fenotípica da glândula mamária, levando a um desenvolvimento precoce da glândula e diferenciação de células epiteliais (KNUDSEN e WHEELOCK, 2005).

A E-caderina é um elemento da família das caderinas conhecida por desempenhar um papel importante na regulação da adesão intercelular em tecidos epiteliais (TAKEICHI, 1991; MATOS et al., 2006). É considerada o principal componente na junção de aderência transmembranosa de células epiteliais de todos os órgãos, como as células epiteliais luminais mamárias (TAKEICHI, 1991). Como a maioria dos tumores de mama, tanto do homem como do cão, são de origem epitelial, as E-caderinas têm sido intensamente estudada em relação à sua função na gênese do tumor (MATOS et al., 2006). Esta molécula parece também ser essencial para a diferenciação e sobrevivência da célula epitelial alveolar, bem como para a função da glândula, pois foi observado que a destruição das E-caderinas do epitélio mamário em lactação resulta em acentuada apoptose com concomitante perda da produção de leite (BOUSSADIA et al., 2002). Estudos utilizando culturas celulares e modelos animais sugeriram que as E-caderinas podem atuar também como molécula supressora de tumor e de invasão neoplásica (KNUDSEN e WHEELOCK, 2005).

\section{Fisiopatologia das caderinas}

Como já mencionado, as E-caderinas unem células epiteliais e as P-caderinas unem células mioepiteliais. Esta expressão diferenciada das E-caderinas e P-caderinas produz dois compartimentos na glândula mamária, com células epiteliais revestindo o lume e células mioepiteliais encobrindo a membrana basal. Mas, as caderinas clássicas não estão envolvidas em ligações entre as células epiteliais e mioepiteliais. Esta função é realizada por uma subfamília de caderinas, as caderinas desmossomais, as quais são componentes transmembranosos dos desmossomos (PITELKA et al., 1973). Os desmossomos unem células epiteliais, células mioepiteliais e os dois tipos de células umas as outras, sendo essenciais para o estabelecimento do arranjo de dupla camada (RUNSWICK et al., 2001). 
Devido às suas interações homofílicas e expressão específica com o tipo celular, as caderinas clássicas iniciam a adesão celular e promovem a seleção da célula, enquanto que as caderinas desmossomais produzem resistência adicional para interações celulares (KNUDSEN e WHEELOCK, 2005). Portanto, a perda da forte adesão que os desmossomos promovem pode desencadear uma importante atuação na disseminação das células tumorais, ou seja, os desmossomos também podem suprimir as metástases (COWIN et al., 2005; KNUDSEN e WHEELOCK, 2005).

Sabe-se que as células epiteliais normais expressam E-caderinas. Entretanto células tumorais que passam por transição de epitelial para mesenquimal podem iniciar uma expressão inapropriada de $\mathrm{N}$-caderinas, proteínas expressas normalmente em tecidos de origem não epitelial que têm sido encontradas em células tumorais mamárias (NIEMAN et al., 1999; CAVALLARO et al., 2002). A expressão das N-caderinas leva a um aumento da migração e invasão celular, estando as E-caderinas presentes ou não (NIEMAN et al., 1999) e a redução das E-caderinas e o aumento das $\mathrm{N}$-caderinas alteram o ambiente celular, mas não a morfologia que acompanha a transição de epitelial para mesenquimal (MAEDA et al., 2005).

A atividade das caderinas é regulada por múltiplos mecanismos, incluindo a interação com as cateninas, eventos de fosforilação e derramamento de conteúdo extracelular (SOLER et al., 2002).

Além de expressarem as E-caderinas, as células epiteliais que delineiam o lume dos ductos e alvéolos expressam também as cateninas associadas $\alpha$-, $\beta$-pacoglobinas e p120 (DANIEL et al., 1995). As E-caderinas são expressas na superfície basolateral destas células epiteliais, no local de contato célula-célula (BRUNETTI et al., 2003). O complexo caderinas-cateninas desempenha um importante papel na morfogênese e arquitetura tecidual e na progressão do câncer. Esses complexos são conhecidos por influenciar as metástases e a invasão por um processo envolvendo a perda da adesão celular (YOSHIDA et al., 2001).

Muitos estudos mostraram que hormônios esteróides também regulam as caderinas. Sabendo-se que uma alteração na expressão do estrógeno pode estar envolvida no aumento da transcrição das E-caderinas, a relação deste hormônio com a expressão das $\mathrm{N}$ - e das E-caderinas tem sido bastante pesquisada (ROWLANDS et al., 2000). Devido a essa repressão das E-caderinas pelo estrógeno, pode-se dizer que este hormônio também é responsável pela manutenção da arquitetura epitelial (COWIN et al., 2005).
Os estudos recentes sobre a função das E-caderinas mostraram uma importância desta molécula também na redução da proliferação celular. Dois mecanismos de redução pelas E-caderinas são conhecidos. No primeiro as E-caderinas inibem a mitose, utilizando o receptor do fator de crescimento epidérmico, o qual regula o nível de p27 nas células. P27 é uma proteína da família dos inibidores das quinases dependentes de ciclina que medeia a interrupção do ciclo celular bloqueando a transição da fase G1 para a S (TOYOSHIMA e HUNTER, 1994). O segundo mecanismo é mediado pelas $\beta$-cateninas, que quando livres exercem atividade de transcrição. A quantidade destas cateninas livres pode ser originada da redução de expressão das E-caderinas ou da mutação de genes (BRUNETTI et al., 2005). As $\beta$-cateninas têm uma função importante na morfogênese e no câncer em seres humanos devido à sua dupla função, pois atuam tanto no complexo de adesividade como na regulação de transdução ou transcrição (HATSELL et al., 2003). Em lesões mamárias caninas, a ausência ou baixa expressão de E-caderinas foi associada com a perda da expressão de $\beta$-cateninas (BRUNETTI et al., 2005).

\section{O complexo caderinas-cateninas}

A adesão celular mediada pelas E-caderinas requer, além da disponibilidade de íons cálcio na superfície celular, da presença adequada de outras proteínas, como as $\alpha$-, $\beta$ - e $\gamma$-cateninas, presentes no lado citoplasmático da membrana plasmática, que ancoram as E-caderinas ao citoesqueleto de actina (TAKEICHI, 1991). Estas associações das caderinas clássicas com suas cateninas formam estruturas identificadas pela microscopia como junções de aderências (KNUDSEN e WHEELOCK, 2005).

Os estudos recentes têm fornecido importantes critérios de mecanismos a respeito das expressões das caderinas e cateninas em cânceres de mama (COWIN et al., 2005), existindo fortes evidências de que estas desempenham um papel vital nesta glândula (KNUDSEN e WHEELOCK, 2005).

As cateninas $\alpha$-, $\beta$ - e p120 formam um complexo com as E-caderinas em células epiteliais mamárias (FIGURA 1). Em geral, a expressão e localização celular das cateninas em cânceres mamários parecem corresponder com a presença ou ausência das E-caderinas (KNUDSEN e WHEELOCK, 2005). 
FIGURA 1: REPRESENTAÇÃO ESQUEMÁTICA DA INTERAÇÃO DO COMPLEXO DE CADERINAS E CATENINAS.
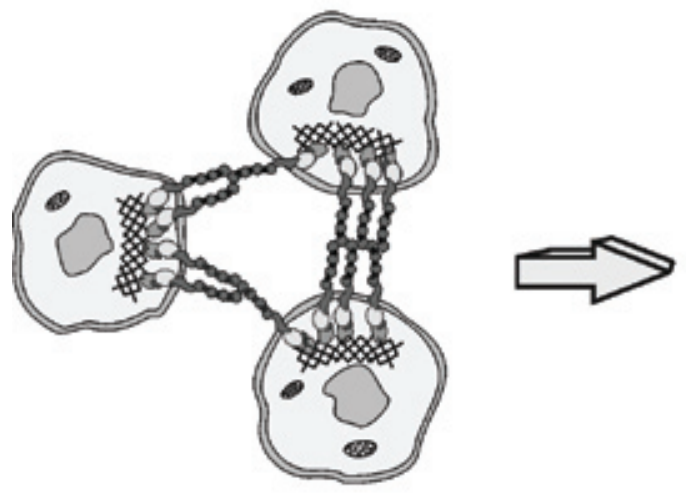

A presença das E-caderinas nos tumores mamários só será funcional se formar um complexo com as cateninas (HATSELL et al., 2003; KNUDSEN e WHEELOCK, 2005). Quando o nível de E-caderinas está normal no tumor, mas as cateninas estão ausentes ou não estão interagindo com as caderinas, as E-caderinas não serão efetivas na função de adesão intercelular no tumor primário (KNUDSEN e WHEELOCK, 2005). A expressão de cateninas pode ser perdida em cânceres de mama com expressão negativa para caderinas e alterações na fosforilação das cateninas podem comprometer a adesão em cânceres caderina-positivos (COWIN et al., 2005). Portanto, a simples presença de cateninas não é suficiente para mostrar que as E-caderinas são plenamente funcionais, já que aquelas podem ser alteradas após a tradução para modificar as funções das caderinas (KNUDSEN e WHEELOCK, 2005).

Além de facilitar a adesão, as cateninas têm também uma função importante em muitas vias de sinalização (HATSELL et al., 2003). Como exemplo, tem-se a dupla função das $\beta$-cateninas já citada anteriormente.

O entendimento das funções das caderinas e de suas cateninas associadas na glândula mamária ainda não é completo. Sabe-se que elas atuam no desenvolvimento e função da glândula mamária normal e que parecem influenciar o câncer de mama e sua evolução clínica. Contudo, novos trabalhos são necessários para se compreender o uso destas proteínas como indicadores de prognósticos no auxílio aos oncologistas para delinear e selecionar a terapia mais efetiva e apropriada (KNUDSEN e WHEELOCK, 2005).

\section{Caderinas como indicadores de prognóstico}

Em Medicina Veterinária, o aumento na casuística e a complexidade na evolução clínica dos tumores de mama nas cadelas têm despertado especial interesse no estudo dos fatores de prognóstico. Determinar o prognóstico acurado do paciente canino portador de neoplasia mamária pode ser difícil, uma vez que o comportamento biológico desses tumores varia consideravelmente. Dessa forma, em animais, a definição de subpopulações de pacientes com evoluções distintas de sobrevida facilitaria não apenas a escolha das melhores condutas terapêuticas a serem adotadas, mas, também, a determinação do prognóstico (KURZMAN e GILBERTSON, 1986).

As E-caderinas, como mediadoras de adesão intercelular, impedem que as células de um tumor primário se soltem e invadam locais próximos ou distantes (KNUDSEN e WHEELOCK, 2005). Portanto, um fator facilitador da disseminação das células tumorais é a redução da expressão dessas moléculas (BRUNETTI et al., 2003; KNUDSEN e WHEELOCK, 2005). Baseando-se nisso, é sugerido que a redução ou a ausência de expressão de E-caderinas nos tumores pode servir como um indicador de prognóstico ruim. No entanto, trabalhos publicados mostram que há divergências a respeito da expressão das E-caderinas como fator prognóstico (KNUDSEN e WHEELOCK, 2005).

A perda de expressão das E-caderinas parece ser um pré-requisito para a ocorrência da disseminação de células tumorais, e pode ser causada por um decréscimo transitório na expressão da molécula durante a fase inicial do desenvolvimento da me- 
tástase ou pela emergência de clones celulares em tumores primários com alterações genéticas levando à reduzida expressão da proteína (VAN DER WURFF et al., 1994). Esta redução de expressão é causada pelo silenciamento epigenético através da repressão de promotores da hipermetilação ou transcrição. Porém, a complexidade das vias intracelulares que regulam o desempenho das caderinas ainda não está completamente entendida, mas muitos fatores chave da transcrição com significativa ação no câncer de mama têm sido identificados (COWIN et al., 2005).

Em seres humanos a associação entre a perda ou redução da atividade de E-caderinas e a progressão de cânceres mamários esporádicos têm sido bem documentadas (COWIN et al., 2005). A expressão das E-caderinas possui correlação, em tumores mamários humanos, com o tipo histológico, fração de crescimento, e expressão de p53 (gene supressor de tumor capaz de ativar proteínas reparadoras do DNA quando este é danificado, reconhecendo o local de dano do DNA na fase G1/S do ciclo celular, e promovendo apoptose da célula danificada quando esta não pode ser reparada) (CHARPIN et al., 1997). No entanto, parece não haver correlação com fatores clínicos como idade do paciente, menopausa e tamanho do tumor (GURIEC et al., 1996). Segundo estes estudos, ainda é controversa a associação das E-caderinas com a presença de metástase nos linfonodos, o grau de diferenciação, condição dos receptores hormonais e expressão de c-erbB-2 (uma oncoproteína com alta expressão em vários adenocarcinomas requerida como indicador de prognóstico ruim) (MATOS et al., 2006). Entretanto, em outros trabalhos, níveis reduzidos de E-caderinas e metástases em linfonodos têm sido correlacionados com o grau de malignidade (HEIMANN et al., 2000). Em pesquisa realizada com carcinomas mamários caninos, observou-se uma relação indireta da expressão das E-caderinas com a de Sialyl-Lewis x (sLex), um carboidrato, considerado marcador tumoral, que tem sua expressão aumentada associada à progressão do tumor e desenvolvimento de metástases. Quando a expressão de E-caderinas estava aumentada, a de sLe ${ }^{x}$ estava diminuída, e vice-cersa (PINHO et al., 2007).

Outros dois estudos, em seres humanos, indicaram que a redução na expressão de E-caderinas em carcinomas ductais infiltrativos de grau I e em carcinomas mamários de grau III foi associada à baixa sobrevida da paciente (TAN et al., 1999; GILLETT et al., 2001). Apesar desses resultados, geralmente, a expressão desta molécula é demonstrada como sendo inversa ao grau histológico e, consequentemente, à diferenciação celular, mas dificilmente é correlacionada com a sobrevida (KNUDSEN e WHEELOCK, 2005).
Em metástases, marcações positivas e negativas de E-caderinas têm sido relatadas. Os estudos realizados com pacientes que apresentaram marcação negativa de E-caderinas nos linfonodos mostraram que a redução na expressão desta proteína está correlacionada com menor período livre de metástases e com prognóstico ruim. Outros relatos indicaram que a simples presença heterogênea da molécula na neoplasia já é indicador de mau prognóstico. Já se observou que células das mais agressivas formas de câncer de mama, câncer de mama inflamatório e carcinoma micropapilar invasivo, muitas vezes apresentam uma expressão aumentada de E-caderinas (KNUDSEN e WHEELOCK, 2005). A expressão mais intensa das E-caderinas nas metástases pode ser devido à fixação das células no novo ambiente, para que possa estabelecer uma arquitetura. Portanto, a re-expressão dessa molécula de adesão por células neoplásicas depois da liberação do local primário pode ser necessária para que estas células fiquem aderidas num órgão distante (BRUNETTI et al., 2003).

Um estudo em seres humanos sugere que os tumores com parcial ou total perda da expressão de E-caderinas são mais infiltrativos, de maior grau de malignidade e mais prováveis de apresentarem disseminação para linfonodos (HEIMANN et al., 2000). Mas, apesar de estudos anteriores terem correlacionado a baixa expressão de E-caderinas com propriedades invasivas, outras investigações têm observado que níveis de $\mathrm{N}$-caderinas e caderinas-11 aumentados são mais intimamente associados com a invasão, motilidade e metástases de células do câncer de mama (NIEMAN et al., 1999). As N-caderinas podem facilitar a invasão e metástase por promoverem uma afinidade da célula tumoral pelas células estromais e endoteliais (COWIN et al., 2005).

Duas pesquisas com tumores mamários caninos encontraram uma associação entre a expressão das E-caderinas e o tipo e diferenciação tumoral (RESTUCCl et al., 1997; REIS et al., 2003). Em outro trabalho realizado com 60 casos de tumores mamários caninos malignos, baseado na função das E-caderinas e das $\beta$-cateninas na invasão e proliferação tumoral, foi observado que a redução destas duas moléculas parece ocorrer paralelamente à ocorrência de invasividade, mas parece não estar correlacionada com a proliferação celular. Além disso, estas proteínas pareceram ser indicadores de prognóstico ruim no concernente a sobrevida (BRUNETTI et al., 2005).

Existe uma significativa associação entre a presença de necrose tumoral e perda da expressão das E-caderinas. Em cânceres mamários em seres humanos, a necrose tumoral é associada à baixa sobrevida e rápida recorrência (MATOS et al., 2006). 
Também foi encontrada uma importante associação entre tumores grandes $(>5 \mathrm{~cm}$ ) e perda da expressão de E-caderinas. A redução na expressão também foi associada por estes autores à ulceração tumoral, que frequentemente ocorre em tumores malignos mais agressivos (RUTTEMAN et al., 2001).

Em um estudo realizado com 77 tumores mamários malignos e 131 linfonodos locais e regionais de 45 fêmeas caninas, demonstrou-se que $48 \%$ dos tumores apresentaram redução na expressão das E-caderinas. A redução da expressão foi significativamente relacionada ao tamanho do tumor e à presença de ulceração, mas não à ocorrência de aderência em tecidos adjacentes. Os tumores com diâmetro menor que 3 centímetros diferenciaram-se dos maiores por apresentarem uma expressão significativamente maior de E-caderinas. As neoplasias com ulcerações apresentaram menor expressão que os não ulcerados. Importante redução de expressão também foi associada com a presença de metástase para linfonodos e presença de necrose (MATOS et al., 2006). No entanto, em cães, a associação das E-caderinas com metástases ainda é controversa, pois em um estudo com cães acometidos por carcinomas mamários com metástase para linfonodos regionais, os resultados mostraram imunomarcação das E-caderinas tanto nos tumores primários como nos linfonodos com metástases (BRUNETTI et al., 2003).

Cânceres caracterizados por crescimento infiltrativo apresentaram expressão significativamente mais baixa que os de crescimento ordenado. Invasão vascular também foi associada com baixa expressão de E-caderinas quando comparada com crescimento expansivo ou crescimento infiltrativo sem invasão vascular (MATOS et al., 2006), porém, essa associação em seres humanos entre a expressão de Ecaderinas e invasão vascular de tumores mamários ainda é contraditória (PARKER et al., 2001; GUPTA et al., 2003). Outros dois estudos indicaram que os tumores bem diferenciados (grau I) apresentaram maior expressão de E-caderinas que os menos diferenciados (graus II e III). Deste modo foi encontrada importante relação na expressão desta proteína com o tipo histológico de neoplasias mamárias caninas. Portanto, existe significativa diferença de expressão entre um grupo de tumores menos diferenciados e um grupo de tumores moderadamente e bem diferenciados (REIS et al., 2003; MATOS et al., 2006).

\section{CONSIDERAÇÕES FINAIS E CONCLUSÕES}

Com o avanço da biologia molecular, novos métodos para determinação de prognóstico, alguns já estabelecidos para seres humanos, têm sido atualmente estudados em tumores mamários caninos, principalmente envolvendo marcadores tumorais (CAVALCANTI e CASSALI, 2006).

Em tumores mamários caninos parece existir uma significativa correlação entre a perda de expressão das E-caderinas e outros indicadores conhecidos de prognóstico ruim, tais como tamanho do tumor, ulceração, tipo histológico, tipo de crescimento, metástase em linfonodos e necrose, indicando que a perda da expressão das E-caderinas pode ter um valor prognóstico em neoplasias mamárias caninas (MATOS et al., 2006). Mas ainda existem divergências quanto ao uso da expressão desta molécula como um indicador de prognóstico independente em cânceres ductais de mama. Em geral, a manutenção da expressão das E-caderinas correlaciona-se com a característica bem diferenciada e não invasiva dos tumores (BERX e VAN ROY, 2001). Entretanto, a manutenção da expressão das E-caderinas já foi observada em cânceres mamários inflamatórios, os quais representam um subtipo de neoplasia extremamente agressivo (CHARAFE-JAUFFRET et al., 2004) e também nas metástases, as quais muitas vezes apresentam alta expressão de E-caderinas (KOWALSKI et al., 2003).

Desta forma, uma opinião emergente é de que ocorram alterações dinâmicas e reversíveis das E-caderinas durante a progressão do carcinoma ductal. A expressão reduzida favoreceria a disseminação, e a expressão recuperada a sobrevivência e reunião das células metastáticas (COWIN et al., 2005). Assim, a expressão das E-caderinas deve ser, provavelmente, dinâmica nas células de cânceres mamários, particularmente já que a perda desta proteína é raramente devida a prejuízos genéticos irreversíveis. Além disso, a expressão das E-caderinas é influenciada pelo estrógeno, um hormônio que tem seus níveis também dinâmicos e que influencia drasticamente a glândula mamária.

Deve-se levar em consideração ainda que a imunomarcação das E-caderinas, pelo método de imuno-histoquímica, representa um segmento do tumor em um dado momento, sendo possível que a diminuição temporária ou localizada das E-caderinas promova separação de células da neoplasia primária e invasão para locais próximos. A re-expressão de E-caderinas pelas células tumorais em um novo ambiente também parece promover a sobrevivência dessas células nos vasos sanguíneos ou no sistema linfático, quando são carreadas para um local distante (KNUDSEN e WHEELOCK, 2005).

A interação entre os patologistas veterinários, clínicos e cirurgiões, desempenha um papel fundamental no estabelecimento da conduta terapêutica e na determinação do prognóstico e do diagnóstico das neoplasias de pequenos animais, pois promove informações acuradas sobre o diagnóstico para, 
então, determinar o prognóstico e tratamento mais adequado. Os clínicos e cirurgiões precisam de conhecimentos de patologia dos tumores para entender as condições neoplásicas e entender as limitações das avaliações histopatológicas no diagnóstico das neoplasias (POWERS, 2001).

A excisão cirúrgica pode ser curativa em cães com o grau mais leve da doença e naqueles com carcinomas in situ. Já cães com tumores maiores e de alto grau, com possibilidade de metástases, podem ser beneficiados pela terapia adicional, como a quimioterapia (SORENMO, 2003). As terapias atuais retardam expressivamente a progressão tumoral, porém a recorrência acaba sendo inevitável, resultando em alta taxa de mortalidade devido à doença (COWIN et al., 2005).

Para garantir que pacientes não sejam tratados com subdoses ou sobredoses de quimioterápicos ou outros tratamentos, a determinação de melhores marcadores de diagnóstico e prognóstico, genes ou proteínas, são necessários para determinação acurada dos resultados clínicos (KNUDSEN e WHEELOCK, 2005).

\section{REFERÊNCIAS}

ABERLE, H.; SCHWARTZ, H.; KEMLER, R. Cadherin-catenin complex: protein interactions and their implications for cadherin function. Journal of Cellular Biochemistry, v.61, p.514-523, 1996.

BERX, G.; VAN ROY, F. The E-cadherin/catenin complex: an important gatekeeper in breast cancer tumorigenesis and malignant progression. Breast Cancer Research, v.3, p.289-293, 2001.

BOUSSADIA, O.; KUTSCH, S.; HIERHOLZER, A.; DELMAS, $\mathrm{V}$;; KEMLER, $R$. E-cadherin is a survival factor for the lactating mouse mammary gland. Mechanisms of Development, v.115, p.53-62, 2002.

BRUNETTI, B.; SARLI, G.; PREZIOSI, R.; LEPROTTI, S.; BENAZZI, C. E-cadherin expression in canine mammary carcinomas with regional lymph node metastases. Journal of Veterinary Medicine. Series A, v.50, p.496-500, 2003.

BRUNETTI, B.; SARLI, G.; PREZIOSI, R.; MONARI, I.; BENAZZI, C. E-cadherin and $\beta$-catenin reduction influence invasion but not proliferation and survival in canine malignant mammary tumors. Veterinary Pathology, v.42, p.781-787, 2005.
CAVALCANTI, M.F.; CASSALI, G.D. Fatores prognósticos no diagnóstico clínico e histopatológico dos tumores de mama em cadelas - revisão. Clínica Veterinária, n.61, p.56-64, 2006.

CAVALLARO, U.; SCHAFFHAUSER, B.; CHRSTOFORI, G. Cadherins and the tumor progression: Is it all in a switch?. Cancer Letters, v.176, p.123-128, 2002.

CHARAFE-JAUFFRET, E.; TARPIN, C.; BARDOU, V.J.; BERTUCCI, F.; GINESTIER, C.; BRAUD, A.C.; PUIG, B.; GENEIX, J.; HASSOUN, J.; BIRNBAUM, D.; JACQUEMIER, J.; VIENS, P. Immunophenotypic analysis of inflammatory breast cancers: identification of an "inflammatory signature". Journal of Pathology, v.202, p.265-273, 2004.

CHARPIN, C.; GARCIA, S.; BOUVIER, C.; DEVICTOR, B.; ANDRAC, L.; CHOUX, R.; LAVAUT, M. E-cadherin quantitative immunocytochemical assays in breast carcinomas. Journal of Pathology, v.181, p.294-300, 1997.

COWIN, P.; ROWLANDS T.M.; HATSELL, S.J. Cadherins and catenins in breast cancer. Current opinion in cell biology, v.17, p.499-508, 2005.

DANIEL C.; STRICKLAND, P.; FRIEDMANN Y. Expression and functional role of $\mathrm{E}$ - and $\mathrm{P}$-cadherins in mouse mammary ductal morphogenesis and growth. Developmental Biology, v.169, p.511-551, 1995.

GILLETT, C.E.; MILES, D.W.; RYDER, K.; SKILTON, D.; LIEBMAN, R.D.; SPRINGALL, R.J.; BARNES, D.M.; HANBY, A.M. Retention of the expression of E-cadherin and catenins is associated with shorter survival in grade III ductal carcinoma of the breast. Journal of Pathology, v.193, p.433-441, 2001.

GURIEC, N.; MARCELLIN, L.; GAIRARD, B.; CALDÉROLI, H.; WILK, A.; RENAUD, R.; BERGERAT, J.P.; OBERLING, F. E-cadherin mRNA expression in breast carcinomas correlates with overall and disease-free survival. Invasion and Metastasis, v.16, p.19-26, 1996.

GUPTA, A.; DESHPANDE, C.G.; BADVE, S. Role of E-cadherins in development of lymphatic tumor emboli. Cancer, v.97, p.2341-2347, 2003. 
HATSELL, R.; ROWLANDS, T.R.; HIREMATH, M.; COWIN, P. The role of $\beta$-catenin and Tcfs in mammary development and neoplasia. J Journal of Mammary Gland Biology and Cancer, v.8, n.2, p.143-156, 2003.

HEIMANN, T.; LAN, F.S.; MCBRIDE, R.; HELLMAN, $S$. Separating favorable from unfavorable prognostic markers in breast cancer: the role of E-cadherin. Cancer Research, v.60, p.298-304, 2000.

KNUDSEN K.A.; WHEELOCK, M.J. Cadherins and the mammary gland. Journal of cellular Biochemestry, v.95, p.488-496, 2005.

KOWALSKI, P.J.; RUBIN, M.A.; KLEER, C.G. $\mathrm{E}$-cadherin expression in primary carcinomas of the breast and its distant metastases. Breast Cancer Research, v.5, p.R217-R222, 2003.

KURZMAN, I.D.; GILBERTSON, S.D. Prognostic factors in canine mammary tumors. Seminars in Veterinary Medicine and Surgery (Small Animal), v.1, p.25-32, 1986.

LODISH, H.; BERK, A.; ZIPURSKY, S.L.; MATSUDAIRA, P.; BALTIMORE, D.; DARNELL, J. Molecular Cell Biology, 4th ed., W.H. Freeman and Company, New York, 1184 pp., 2000.

MAEDA, M.; JOHNSON K.R.; WHEELOCK, M.J. Cadherin switching: Essencial for behavioral but not morphological changes in epithelial to mesenchymal transition. Journal of Cell Science, v.118, p.873887, 2005.

MATOS, A.J.F.; LOPES, C.; CARVALHEIRA, J.; SANTOS, M.; RUTTEMAN, G.R.; GÄRTNER, F. E-cadherin expression in canine malignant mammary tumours: relationship to other clinico-pathological variables. Journal of Comparative Pathology, v.134; p.182-189, 2006.

NIEMAN, M.T.; PRUDOFF, R.S.; JOHNSON, K.R.; WHEELOCK, M.J. N-cadherin promotes motility in human breast cancer cells regardless of their E-cadherin expression. The Journal of Cell Biology, v.147, p.631-643, 1999.

PARKER, C.; RAMPAUL, R.S.; PINDER, S.E.; BELL, J.A.; WENCYK, P.M.; BLAMEY, R.W.; NICHOLSON, R.I.; ROBERTSON, J.F. E-cadherin as a prognostic indicator in primary breast cancer. British Journal of Cancer, v.85, p.1958-1963, 2001.
PIEKARZ, C.H. Expressão da E-caderina no prognóstico de neoplasias mamárias em cadelas. Curitiba, 2007. 73pp. Dissertação (Mestrado em Ciências Veterinárias), Curso de Medicina Veterinária, Universidade Federal do Paraná.

PINHO, S.S.; MATOS A.J.; LOPES, C.; MARCOS, N.T.; CARVALHEIRA, J.; REIS, C.A.; GÄRTNER. F. Sialyl Lewis $x$ expression in canine malignant mammary tumours: correlation with clinicopathological features and E-Cadherin expression. BMC Câncer, v.6, n.7, p.124, 2007.

PITELKA, D.R.; HAMAMOTO, S.T.; DUAFALA, J.G. NEMANIC, M.K. Cell contacts in the mouse mammary gland. The Journal of Cell Biology, v.56, p.797-818, 1973.

POWERS, B.E. The Pathology of Neoplasia. In: WITHROW, S.J.; MACEWEN E.G. Small Animal Clinical Oncology. Philadelphia: W.B. Saunders, p.4-17, 2001.

RADICE, G.; FERREIRA-CORNWALL, C.; ROBINSON, S.D.; RAYBURN H.; CHODOSH, L.A.; TAKEICHI, M.; HYNES, R.O. Precocious mammary gland development in P-cadherin-deficient mice. The Journal of Cell Biology, v.139, p.1025-1032, 1997.

RADICE, G.L.; SAUER, C.L.; KOSTETSKII, I.; PERALTASOLER, A.; KNUDSEN, K.A. Inappropriate $P$-cadherin expression in the mouse mammary epithelium is compatible with normal mammary gland function. Differrentiation, v.71, p.361-373, 2003.

REIS, A.L.; CARVALHEIRA, J.; SCHMITT, F.C.; GÄRTNER, F.Immunohistochemical study of the expression of $\mathrm{E}$-cadherin in canine mammary tumours. Veterinary Record, v.152, p.621-624, 2003.

RESTUCCI, B.; PAPPARELLA, S.; DE VICO, G.; MAIOLINO, P. E-cadherin expression in normal and neoplastic canine mammary gland. Journal of Comparative Pathology, v. 116, p. 191-202, 1997.

ROWLANDS, T.M.; SYMONDS, J.M.; FAROOKHI, R.; BLASCHUK, O.W. Cadherins: crucial regulators of structure and function in reproductive tissues. Reviews of Reproduction, v.5, p.53-61, 2000. 
RUNSWICK, S.K.; O'HARE, M.J.; JONES, L.; STREULI, C.H.; GARROD, D.R. Desmosomal adhesion regulates epithelial morphogenesis and cell positioning. Nature Cell Biology, v.3, p.823830, 2001.

RUTTEMAN, G.R.; WITHROW, S.J.; MACEWEN, E.G. Tumors of the mammary gland. In: WITHROW, S.J.; MACEWEN, E.G. W.B. Small Animal Clinical Oncology. 3.ed. Philadelphia: W.B. Saunders, 2001, p.455-477.

SOLER, A.P.; RUSSO, J.; RUSSO, I.H.; KNUDSEN, K.A. Soluble fragment of P-cadherin adhesion protein found in human milk. Journal of Cellular Biochemistry, v.85, p.180-184, 2002.

SORENMO, K. Canine mammary gland tumors. The Veterinary clinics of North America. Small animal practice, v. 33, p. 573-596, 2003.

TAKEICHI, M. Cadherin cell adhesion receptors as a morphologenetic regulator. Science, v.251, p.14511455, 1991.

TAN, D.S.P.; POTTS, H.W.W.; LEONG, A.C.K.; GILLETT, C.E.; SKILTON, D.; HARRIS, W.H.; LIEBMANN, R.D.; HANBY, A.M. The biological and prognostic significance of cell polarity and E-cadherin in grade I infiltrating ductal carcinoma of the breast. Journal of Pathology, v.189, p.20-27, 1999.
TOYOSHIMA, H., HUNTER, T. P 27, a novel inhibitor of $\mathrm{G} 1$ cyclin-Cdk protein kinase activity, is related to p21. Cell, v. 78, n. 1, p. 67-74, 1994.

VAN DER WURFF, A.A.M.; ARENDS, W.; VAN DER LINDEN, E.P.M. KATE, J.T.; BOSMAN, F.T. L-CAM expression in lymph node and liver metastases of colorectal carcinomas. Journal of Pathology, v.172, p.177-182, 1994.

YOSHIDA, R.; KIMURA, N.; HARADA, Y.; OHUCHI, $N$. The loss of E-cadherin, $\alpha$ - and $\beta$-catenin expression is associated with metastasis and poor prognosis in invasive breast cancer. International Journal of Oncology, v.18, p.513-520, 2001.

Recebido para publicação:

$04 / 10 / 2007$

Aprovado: $23 / 04 / 2008$ 